\title{
Use of LinkedIn in teaching and labour monitoring of the Master in Hotel Companies Management
}

\author{
Babinger, Frank $^{a}$; Maseda, Araceli ${ }^{\mathrm{b}}$; Susaeta, Lourdes ${ }^{\mathrm{b}}$ and De las Heras, Victoria ${ }^{\mathrm{c}}$ \\ ${ }^{a}$ Department of Regional Geographic Analysis and Physical Geography, Complutense \\ University of Madrid, Spain, ${ }^{b}$ Department of Business Organization, Complutense \\ University of Madrid, Spain, ${ }^{c}$ Department of Financial Economics and Accounting II \\ (Accounting), Complutense University of Madrid, Spain.
}

\begin{abstract}
The present paper explores the use of the professional social network LinkedIn in the teaching of official masters. It is based on two projects of teaching innovation that are based on the information contained in the alumni profiles of the Master in Hotel Companies Management of the Complutense University of Madrid. Thanks to its analysis, valuable information about the insertion and career of the master's graduates is obtained, while it implies a greater interrelation between the academic and labour world. In this way, the quality of the teaching-learning process can be verified and improved with the approach of the labour world and the incorporation of the experiences of alumni to the classroom as an enrichment of regulated teaching.
\end{abstract}

Keywords: LinkedIn, social networks, masters, graduates, job placement. 


\section{Introduction}

At present, the use of social networks has become an essential communication tool in the professional world that can not left out the university, and much less the teaching reality in master's degrees. For this reason, it is interesting and essential to explore which social networks are the most appropriate to foster the labor insertion of the master's students. Among the social networks in the 2.0 environment, it is worth highlighting the professional network LinkedIn as a pioneer in its applications to bring professionals in touch.

Within the Master in Hotel Companies Management of the Complutense University of Madrid, the need to promote the knowledge and the use of this network as a facilitator for the labor insertion of its students has been detected.

Given this need, and considering it essential as part of the competencies to be achieved in the program, several teachers of the master took the initiative to develop an educational innovation project to explore this field. As a result of this concern, the project "Utilization of the LinkedIn social network for academic and professional purposes for students of the Master in Hotel Companies Management" (Babinger et al., 2015) was developed which the objective to create a profile of the Master in Hotel Companies Management in LinkedIn with an associated group.

The specific objectives of the project were its diffusion:

- Among the teachers who teach classes in the master's degree, expandable to all teachers who have concordant interests in the Complutense University of Madrid.

- Both current and former students of the master, so that they could benefit from existing contacts.

- To other professionals who share the same concerns, through network operation itself.

Both teachers and students could be added to the created group, while it was open to anyone to enrich mutual knowledge and the flow of information and ideas.

The objective was to use it as a permanent communication channel with new and old students, in which news, reports and any other information of interest were posted while it could also serve as an additional channel of possible job offers for students by improving their network.

Following the good results achieved in this project, the opportunity was raised to develop a second educational innovation project entitled "Analysis and follow-up of the insertion and trajectory of the graduates of the Master Hotel Companies Management of the Complutense University of Madrid" (Innova-Docencia, No. 110, 2016-2017), which is currently being implemented and presented in this communication. 


\section{Background}

The LinkedIn network provides benefits to both students, who are looking for job opportunities after their education, and to companies, as it allows them to manage the search for potential candidates in an agile and efficient way.

Some of the reasons why the use of LinkedIn is essential in the work placement of students are, among others: the visibility it provides to users, network creation, access to current job information, personal brand generation and the power to consume content generated by its own network and related to its professional activity. All of this provides students with a direct, effective, free or low-cost contact with labour world.

The use of the LinkedIn network is, therefore, a fundamental training tool for the students since it gives them the possibility of entering labour work in a direct and simple way.

With regard to companies, and taking as reference Chiavenato (2011), the management of the HR system in a company is integrated by basic processes such as recruitment and selection of staff, job design, incentive system and remuneration, the development of employees' professional careers and the evaluation of people, among others.

Within this management, the process of recruitment and selection of candidates is the fundamental process on which other processes pivot, since if the selection and recruitment are not carried out in an adequate way, it is difficult for the HR system to develop candidate, implement the incentive system, etc. Therefore, all these processes will depend on it (Bretones \& Rodríguez, 2008) and the company must invest in the necessary resources.

Due to this, the companies, immersed in a globalized and very competitive environment, strive to attract the talent, using for this the use of new technologies of the information and communication, through Internet, optimizing this process (González, 2005) .

In a study by Deloitte (2009), it was identified that $23 \%$ of companies were already using social networks in their recruitment and selection process, and according to a study by Media Bistro (2014) the number of active LinkedIn users in the world is 270 million.

According to the aforementioned study, $45 \%$ of LinkedIn users use it daily, having helped $64 \%$ of users to develop their professional career. Regarding companies, $80 \%$ use the LinkedIn network to attract new talent.

We are therefore faced with an inevitable e-recruitment, and students, especially postgraduate ones, must be trained to act in this environment (Rico, 2015).

According to the International Labor Organization (ILO) employability is "the ability to secure and retain employment: to tune into the labor market, to be able to change jobs without difficulty or to find a job" (International Labor Organization Work, 2014). In 
addition, the selection of personnel is one of the main functions by which an organization chooses from among a list of candidates the person who best meets the criteria required to fill the available position, taking into account the current human resources market conditions (Werther \& Davis, 2008). The LinkdIn social network is therefore an appropriate tool for employability and selection of staff.

\section{Methodology}

The method used in the innovation and improvement of teaching quality projects is fundamentally qualitative, through the exploration of information published by users, in this case of alumni of the master, in the LinkedIn network. Subsequently, and after carrying out an organization of the information, it is analyzed statistically by means of a descriptive process applied to the totality of the data obtained. The method to be followed is to obtain frequencies and represent them by means of histograms, performing a statistical analysis by correspondences, to detect whether or not there are some dominant variables in the labor insertion of graduates.

\subsection{Process}

Prior to the implementation of the project, the research team, of an interdisciplinary nature, thought it appropriate to be enriched by representatives of the administration and services staff and students of the master's degree, in order to achieve a broader focus on the subject.

The procedure designed for the present research, includes the search and exploration of the master alumni profiles in LinkedIn, for which the work carried out in the previous project is essential. In its development, the network was used as a platform of students, so that it was possible to contact all students of previous promotions with an updated database.

This resulted in the establishment of a professional network of new and old students, teachers, professionals, institutions and companies that broadened the contacts of all of them and resulted in a new way of applying social networks to the teaching of professional masters.

The project currently under way, and with the aim of knowing the insertion and career of the students of the master's degree, specifically analyzes where they currently work, from when they do it and in what work position they are. Also considered is their career if they have worked in several companies, the time they have taken to find their first job and if it is related to the degree. Finally, given the diversity of the master's degree, we want to investigate whether there are differences by gender and nationality in the achievement of quality work. 


\section{Results}

First of all it should be mentioned that this is a project that is currently in the development phase, so quantum results can not yet be offered as a whole. However, it should be noted that all the graduates of the master's degree have been contacted, 261 students in total, who have joined the master's network and from which the necessary information for the present project is being obtained.

The expected results are not limited to knowing the work environment in which the alumni are located, but to have a background that includes the verification of the quality of teaching to elucidate the extent to which the teaching offered in the master is useful for their professional future.

The Master in Hotel Companies Management of the Complutense University of Madrid is a degree that has as its main challenge the education of highly trained professionals. Therefore, it is understood that an effective labor insertion in companies of the sector could be used to corroborate the quality and usefulness of the offered teaching.

Knowing this scenario, it would be possible to evaluate if the learning contained in the curricula is adapted to the graduates' work reality and to propose changes and appropriate modifications that result in the improvement of the teaching quality.

In addition, the project also aims to strengthen the use of the network created in a bidirectional way: not only to facilitate the incorporation of students into labour world, but also to add the professional sector to teaching the master. This would take advantage of the contacts created, to organize activities such as continuity programs that would include visits to companies where former students work, invitations to give talks, conferences or seminars and to participate in round tables.

\section{Conclusions}

The LinkedIn professional network can be considered a good complement to the regulated teaching in the masters to achieve a greater interrelation between the academic and labour world. However, it has been detected that this relationship is still insufficiently internalized, which shows the need to intensify its use in master's degrees.

The results of the detailed analysis of the work trajectories followed by the different nationalities that make up the master's students will allow a personalized attention to both foreign and national students, whether they are currently studying the master's degree or those who study in a future 
Based on established contacts, a specific network of old and new students can be created with whom to organize concrete and periodic activities for the labor insertion. This network promotes the recommendations among the graduates and improves the teaching quality of the master to know the real work needs of the graduates.

So the main conclusion of the ongoing project, beyond the results being analyzed at present, is the positive impact for the teaching-learning process with the incorporation of alumni experiences in the classroom, as an enrichment of regulated teaching.

On the other hand, an additional conclusion of the research is its applicability to other degrees, since the relation with the labour market is established without doubt, independently of the branch of knowledge.

\section{References}

Babinger, F., Susaeta, L., Maseda Moreno, A., De las Heras, M. V., \& Castañeda, J. E. (2015). e-prints UCM. (UCM, Editor) Obtenido de http://eprints.ucm.es/34874/

Bretones, D., \& Rodríguez, A. (2008). Reclutamiento y seleción de personal. España: Ediciones Pirámide.

Chiavenato, I. (2011). Administración de recursos humanos (9a edición ed.). México: McGraw Hill.

González, R. (2005). Nuevas tecnologías aplicadas a la gestión de RRHH. Las TIC como herramienta permanete del capital humano. ( $1^{\mathrm{a}}$ edición ed.). España: Ideas propias.

Organización internacional del trabajo. (2014). Promover el empleo, proteger a las personas.

Rico, J. (2015). Obtenido de http://revistaemprendedor.com.ve/es/reclutamiento-1-0-vs-elreclutamiento- 2-0/

Sáez, F., \& Torres, C. (2007). Obtenido de ttp://www.fundipe.es/publicaciones.html

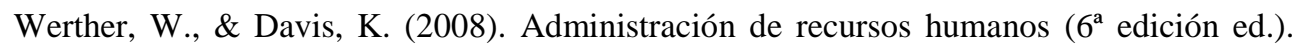
Mexico: McGraw. Hill. 